Research Article

\title{
The Anticonvulsant Effect of Hydroethanolic Leaf Extract of Calotropis procera (Ait) R. Br. (Apocynaceae)
}

\author{
Ernest Obese $\mathbb{D}^{1},{ }^{1}$ Robert Peter Biney $\mathbb{D}^{1},{ }^{1}$ Isaac Tabiri Henneh $\left(\mathbb{D},{ }^{1}\right.$ \\ Emmanuel Awintiig Adakudugu $\mathbb{B}^{1},{ }^{1}$ Daniel Anokwah $\mathbb{D}^{1},{ }^{1}$ Lovia Serwaa Agyemang $\mathbb{B}$, ${ }^{2}$ \\ Eric Woode ${ }^{(D)}{ }^{3}$ and Elvis Ofori Ameyaw ${ }^{1}{ }^{1}$ \\ ${ }^{1}$ School of Pharmacy and Pharmaceutical Sciences, College of Health and Allied Sciences, University of Cape Coast, \\ Cape Coast, Ghana \\ ${ }^{2}$ Department of Biomedical Sciences, School of Allied Health Sciences, College of Health and Allied Sciences, University of Cape Coast, \\ Cape Coast, Ghana \\ ${ }^{3}$ Department of Pharmacology, Faculty of Pharmacy and Pharmaceutical Sciences, University of Allied Health Sciences, Ho, Ghana
}

Correspondence should be addressed to Elvis Ofori Ameyaw; eameyaw@ucc.edu.gh

Received 16 February 2021; Revised 31 May 2021; Accepted 19 June 2021; Published 28 June 2021

Academic Editor: J. Michael Wyss

Copyright (c) 2021 Ernest Obese et al. This is an open access article distributed under the Creative Commons Attribution License, which permits unrestricted use, distribution, and reproduction in any medium, provided the original work is properly cited.

\begin{abstract}
A number of currently used drugs have been obtained from medicinal plants which are a major source of drugs. These drugs are either used in their pure form or modified to a semisynthetic drug. Drug discovery through natural product research has been fruitful over the years. Traditionally, Calotropis procera is used extensively in the management of epilepsy. This study is conducted to explore the anticonvulsant effect of a hydroethanolic leaf extract of Calotropis procera (CPE) in murine models. This effect was evaluated using picrotoxin-induced convulsions, strychnine-induced convulsions, and isoniazid- and pilocarpine-induced status epilepticus in mice of both sexes. The results showed that CPE (100-300 mg/kg) exhibited an anticonvulsant effect against strychnine-induced clonic seizures by significantly reducing the duration $(p=0.0068)$ and frequency $(p=0.0016)$ of convulsions. The extract $(100-300 \mathrm{mg} / \mathrm{kg})$ caused a profound dose-dependent delay in the onset of clonic convulsions induced by picrotoxin $(p<0.0001)$ and tonic convulsions $(p<0.0001)$ in mice. The duration of convulsions was reduced significantly also for both clonic and tonic $(p<0.0001)$ seizures as well. CPE $(100-300 \mathrm{mg} / \mathrm{kg})$, showed a profound anticonvulsant effect and reduced mortality in the pilocarpine-induced convulsions. $\mathrm{ED}_{50}(\sim 0.1007)$ determined demonstrated that the extract was less potent than diazepam in reducing the duration and onset of convulsions but had comparable efficacies. Flumazenil-a GABA receptor antagonist-did not reverse the onset or duration of convulsions produced by the extract in the picrotoxin-induced seizure model. In isoniazid-induced seizure, CPE $\left(300 \mathrm{mg} \mathrm{kg}^{1}\right.$, p.o. $)$ significantly $(p<0.001)$ delayed the onset of seizure in mice and prolonged latency to death in animals. Overall, the hydroethanolic leaf extract of Calotropis procera possesses anticonvulsant properties.
\end{abstract}

\section{Introduction}

Epilepsy is a neurological condition that affects people of various age categories and is marked by excessive or abnormal electric activity occurring in either a portion or all of the brain [1]. Seizures that can happen spontaneously and repeatedly are known as outward signs of epilepsy. The seizures may well be caused by various conditions such as stroke, brain tumour, head injury, or infection of the central nervous system [1]. It is projected that about fifty million individuals worldwide currently live with epilepsy and the disorder is responsible for one percent of the global burden of diseases [2] and is typically higher in low- and middleincome countries [3].

Despite the broad range of pharmacological agents approved for patients with epilepsy, many people are still nonresponsive or refractory to antiepileptic drug therapy, rendering pharmacoresistance one of the most significant 
clinical issues in the management of the disease [3]. Also, these treatments only resolve epilepsy symptoms and do not properly prevent the occurrence of seizures or permanently stop seizures [4]. New, better, and safer antiepileptic drugs (AEDs) with enhanced clinical profiles need to be developed. Traditional medicine has contributed greatly to the discovery of many drugs, including morphine, digoxin, quinine, and atropine [5].

Plant extracts are some of the most appealing sources of fresh drugs, and promising outcomes have been shown for epilepsy therapy. Examples include Antiaris toxicaria, Pseudospondias microcarpa, and Mallotus oppositifolius [6-8]. Since it is estimated that around $80 \%$ of the population in the developing world use herbal remedies for their primary health care needs [9], conditions like epilepsy and pain are usually managed using herbs. Plant products traditionally used in the therapy of epilepsy can serve as a basis for identifying and developing alternative antiepileptics, as they may contain bioactive compounds that can mitigate seizures [10]. Calotropis procera is another example of medicinal plants used traditionally in the management of epilepsy [11].

In our laboratory, Calotropis procera extract showed a significant central nervous system (CNS) depressant effect and the ability to delay and reduce the frequency of seizures in a primary neuropharmacological screening test. With this, in combination with its conventional use in the management of epilepsy and other CNS disorders [11], the extract's anticonvulsant property can be further assessed to confirm its anticonvulsant qualities. It has also been shown to have significant anti-inflammatory and antinociceptive properties, and since pain and inflammation are acutely manifested in epilepsy $[12,13]$, these effects may augment the possible anticonvulsant effect of $C$. procera in epilepsy management.

The chemical fingerprint of herbal products is an accepted strategy by the World Health Organisation (WHO) to authenticate and assessment of the quality of medicinal plants [14]. Although there are several analytical techniques for developing fingerprint, High-Performance Liquid Chromatography (HPLC) is the most popular technique which provides a rapid fingerprint for identifying and assessing the quality of medicinal plants [15].

The present study was conducted to develop an HPLC fingerprint and further explore the anticonvulsant potentials of the hydroalcoholic extract of the leaves of $C$. procera by employing acute seizure models using agents such as picrotoxin and strychnine. The pilocarpine (a human temporal lobe epilepsy model) and isoniazid models of status epilepticus were also employed in characterizing the anticonvulsant effect of the extract. The possible involvement of the benzodiazepine/gamma amino butyric acid (GABA) receptor complex in the mechanism of action of the extract was also investigated.

\section{Materials and Methods}

2.1. Plant Collection and Extraction. Fresh leaves of Calotropis procera were collected from Iture $\left(5^{\circ} 05^{\prime} 54.6^{\prime \prime} \mathrm{N}, 1^{\circ} 18^{\prime}\right.$ $48.7^{\prime \prime} \mathrm{W}$ ), a town near the University of Cape Coast (UCC), from August to December 2015. Leaves of C. procera were authenticated by Mr. Fynn, a botanist, at the School of Biological Sciences Herbarium, University of Cape Coast, and the voucher number UCC/SBSH/15/M044 was assigned. A hydroalcoholic extract was produced as previously described $[12,16]$. The leaves were air-dried for fourteen days and powdered. An amount of $200 \mathrm{~g}$ of the powdered leaves was soaked with $2 \mathrm{~L}$ of $70 \%$ ethanol for $72 \mathrm{~h}$, filtered, and concentrated using a rotary evaporator (Rotavapor R-215, BÜCHI Labortechnik AG, Flawil, Switzerland) under reduced pressure and temperature $\left(50^{\circ} \mathrm{C}\right.$ ). The extract, CPE (Calotropis procera extract), was further dried and preserved in a desiccator containing activated silica until it was ready for use. The yield obtained was $4.8 \% w / w$. The extract was reconstituted for use in the experiments by gently triturating to prepare a solution of it with distilled water as the vehicle.

2.2. HPLC Fingerprint. The freshly prepared extract $(200 \mathrm{mg})$ was reconstituted in $10 \mathrm{~mL}$ of $70 \% v / v$ ethanol to obtain a stock solution $(2 \% w / v)$. About $2 \mathrm{~mL}$ of the solution was filtered through a $0.45 \mu \mathrm{m}$ membrane filter into the sample vial.

The HPLC analysis of the extract was carried out on a PerkinElmer Flexar system consisting of a binary pump, Photo Diode Array detector, autosampler, and online degasser. The separation was carried out on the Zorbax 300SB-C18 analytical column $(4.6 \times 250 \mathrm{~mm}, 5 \mu \mathrm{m})$ from Agilent Technologies with an injection volume of $20 \mu \mathrm{L}$ and an acquisition wavelength of $280 \mathrm{~nm}$. The mobile phase comprising $0.05 \%$ trifluoroacetic acid (A) and methanol (B) was employed with gradient elution at a flow rate of $1 \mathrm{~mL} / \mathrm{min}$ at ambient temperature. The gradient elution was programmed as follows: 0-3 min, 15\% B; 3-23 min, 90\% B; 23-26 min, 90\% B; 26-27 min, $15 \% \mathrm{~B}$; and $27-32 \mathrm{~min}, 15 \% \mathrm{~B}$ [16].

2.3. Animals. ICR mice of both sexes (20-25 g) were acquired from the Noguchi Memorial Institute for Medical Research and cared for in the Animal House Department. They were kept in the animal house of the School of Biological Sciences, University of Cape Coast (UCC) for seven days to acclimatize before the experiments. The animals were housed in cages $\left(34 \times 47 \times 18 \mathrm{~cm}^{3}\right)$ with softwood shavings as bedding and were maintained at a $12 \mathrm{~h}$ light-dark cycle. They had free access to food and water. The studies conducted were following the National Institute of Health (NIH) Guidelines for Care and Use of Laboratory Animals with approval from the Department of Pharmacology Ethics Committee.

2.4. Drugs and Chemicals. Diazepam (DZP) (>99\% (HPLC), solid), picrotoxin (PTX) (>97.5\% (HPLC), solid), strychnine (STR) (98\% powder, solid), isoniazid (analytical standard, $\geq 99 \%$ (TLC)), and pilocarpine (99\% (titration), powder) were purchased from Sigma-Aldrich Chemie $\mathrm{GmbH}$ (Eschenstrasse) Germany. Flumazenil (FLU) was purchased from Roche, (Basel) Switzerland (>99\% (HPLC), solid).

2.5. Strychnine-Induced Seizure Test. The experimental model used was as described previously [8, 17]. Briefly, strychnine seizures were induced in male ICR mice $(n=7)$ by the injection of strychnine nitrate, $(0.5 \mathrm{mg} / \mathrm{kg}$ i.p. $) 1 \mathrm{~h}$ after administration of the extract $(30-300 \mathrm{mg} / \mathrm{kg}$, p.o.) or $30 \mathrm{~min}$ after diazepam $(0.1-1.0 \mathrm{mg} / \mathrm{kg}$, i.p.) administration. The 


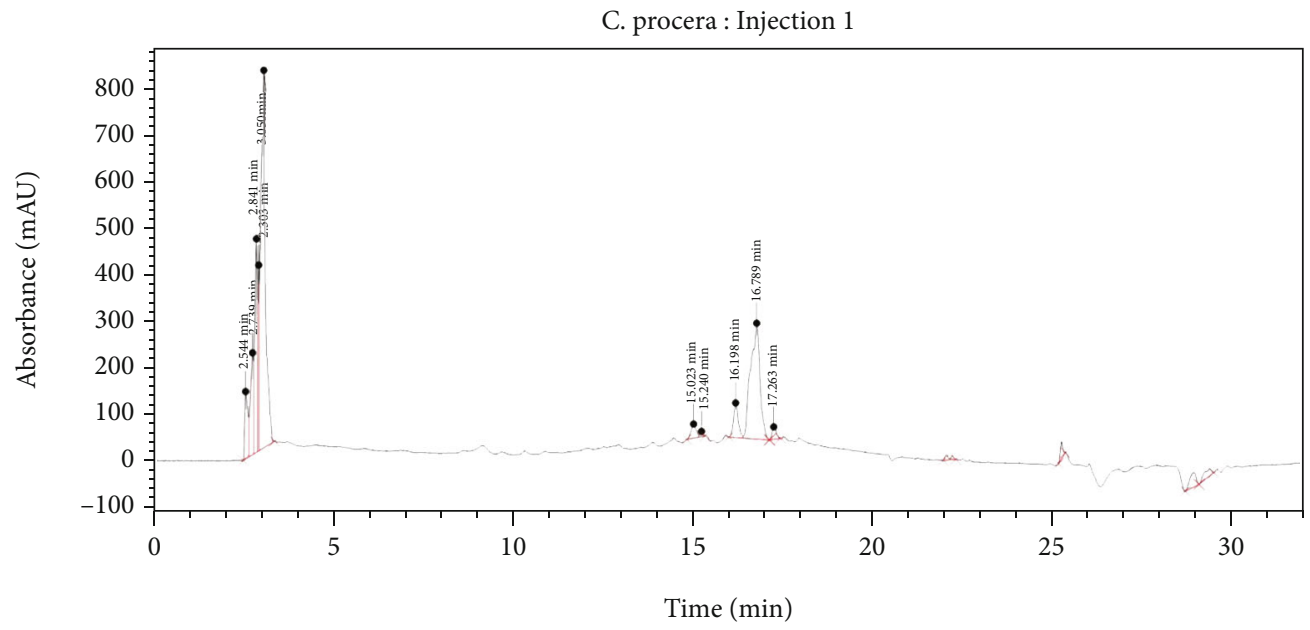

FIGURE 1: HPLC chromatogram of the $70 \%$ hydroethanolic extract of C. procera leaves.

TABLe 1: Peaks representing various constituents in CPE.

\begin{tabular}{lccc}
\hline Peak \# & RT $(\mathrm{min})$ & Area & Height \\
\hline 1 & 2.544 & $816,223.3$ & $144,908.7$ \\
2 & 2.739 & $1,319,146.6$ & $219,099.5$ \\
3 & 2.841 & $2,268,039.8$ & $460,169.7$ \\
4 & 2.903 & $893,419.5$ & $399,447.2$ \\
5 & 3.050 & $7,357,355.7$ & $811,648.1$ \\
6 & 15.023 & $305,158.0$ & $30,711.5$ \\
7 & 15.240 & $56,255.6$ & $10,796.5$ \\
8 & 16.198 & $679,475.5$ & $73,862.5$ \\
9 & 16.789 & $4,618,429.7$ & $249,179.4$ \\
10 & 17.263 & $207,809.2$ & $26,543.7$ \\
\hline
\end{tabular}

frequency, duration, and also latency to myoclonic jerks were recorded for extract-treated groups and the diazepam group compared to the saline-treated animals (control). These were observed through video recording (Sony-Handycam, model: HDRCX675/B, Tokyo, Japan) for $30 \mathrm{~min}$. Animals were tracked using the behavioural analysis software, JWatcher ${ }^{\mathrm{TM}}$ version 1.0 (University of California, Los Angeles, USA, and Macquarie University, Sydney, Australia. Available at http://www.jwatcher.ucla.edu).

2.6. Pilocarpine-Induced Status Epilepticus. This experiment followed a procedure previously described $[8,18]$. Pilocarpine $(300 \mathrm{mg} / \mathrm{kg}$, i.p.) was administered to induce seizures by injection to ICR mice $(n=7)$. CPE $(30-300 \mathrm{mg} / \mathrm{kg}$, p.o. $)$ or diazepam $(0.1-1.0 \mathrm{mg} / \mathrm{kg}$, i.p.) or normal saline $(10 \mathrm{~mL}$ $\mathrm{kg}^{-1}$ p.o.) was administered $1 \mathrm{~h}$ after oral or $30 \mathrm{~min}$ after i.p. administration before induction of seizures. N-Butylbromide hyoscine $(1 \mathrm{mg} / \mathrm{kg}$, i.p.) was administered $30 \mathrm{~min}$ prior to induction to counter the peripheral autonomic effects produced by pilocarpine. After the injection of pilocarpine, the animals were placed separately into the transparent Plexiglas testing chamber and the latency to and duration of clonic tonic seizures were observed through video recordings and tracked as outlined in Section 2.5. Dose-response curves were plotted and $\mathrm{ED}_{50}$ (a measure of anticonvulsant potency) and $E_{\max }$ (a measure of efficacy) were obtained from the curves.

2.7. Isoniazid-Induced Seizure Model. The method was as previously described [19]. Animals were adapted to the chamber for $1 \mathrm{~h}$ before receiving treatment with either $\mathrm{CPE}$ (30-300 mg/kg, p.o.), diazepam (0.1-1 mg/kgi.p.), or saline $(10 \mathrm{~mL} / \mathrm{kg}$, i.p.). Seizures were induced with isoniazid (INH) (300 mg/kg, p.o.) $30 \mathrm{~min}$ or $1 \mathrm{~h}$ after i.p. or p.o. treatment, respectively. Animals were observed and tracked as previously described in Section 2.5.

2.8. Picrotoxin-Induced Seizure Model. The procedure used was the same as discussed in the pilocarpine seizure test described in Section 2.5 except that seizures induced in mice $(n=7)$ were by administration of picrotoxin $3 \mathrm{mg} / \mathrm{kg}$, i.p. [6] $30 \mathrm{~min}$ and $1 \mathrm{~h}$ after treatment with diazepam $(0.1-1 \mathrm{mg} / \mathrm{kg}$, i.p.) and CPE (30-300 mg/kg, p.o.), respectively. Animals in the control group received normal saline $(10 \mathrm{~mL} / \mathrm{kg}$, p.o.). The latency to tonic convulsions, latency to myoclonic jerks, and also the frequency and duration of tonic convulsions were recorded from the videos for each mouse as previously described in Section 2.5.

2.9. Involvement of the GABAergic System. A selective benzodiazepine receptor antagonist, flumazenil (FLU), was used to investigate the involvement of $\mathrm{GABA}_{\mathrm{A}}$ receptors in the anticonvulsant mechanism of CPE. Animals $(n=7)$ received CPE (100 mg/kg, p.o.), diazepam (0.3 mg/kg, i.p.), flumazenil $(2 \mathrm{mg} / \mathrm{kg})$, and normal saline $(10 \mathrm{~mL} / \mathrm{kg}$, p.o. $) 30 \mathrm{~min}$ before the administration of picrotoxin ( $3 \mathrm{mg} / \mathrm{kg}$ i.p.). The last two groups were given flumazenil $(2 \mathrm{mg} / \mathrm{kg}$, i.p.) $5 \mathrm{~min}$ before the administration of CPE $(100 \mathrm{mg} / \mathrm{kg}$, p.o. $)$ or diazepam $(0.3 \mathrm{mg} / \mathrm{kg}$, i.p.) and $65 \mathrm{~min}$ or $35 \mathrm{~min}$ before the injection of picrotoxin (3 $\mathrm{mg} / \mathrm{kg}$, i.p.), respectively. The latency to frequency and duration of clonic convulsions were tracked as described in Section 2.5.

2.10. Data Analysis. Data from the experiments were presented as the mean \pm standard error of mean (S.E.M.). Two- 


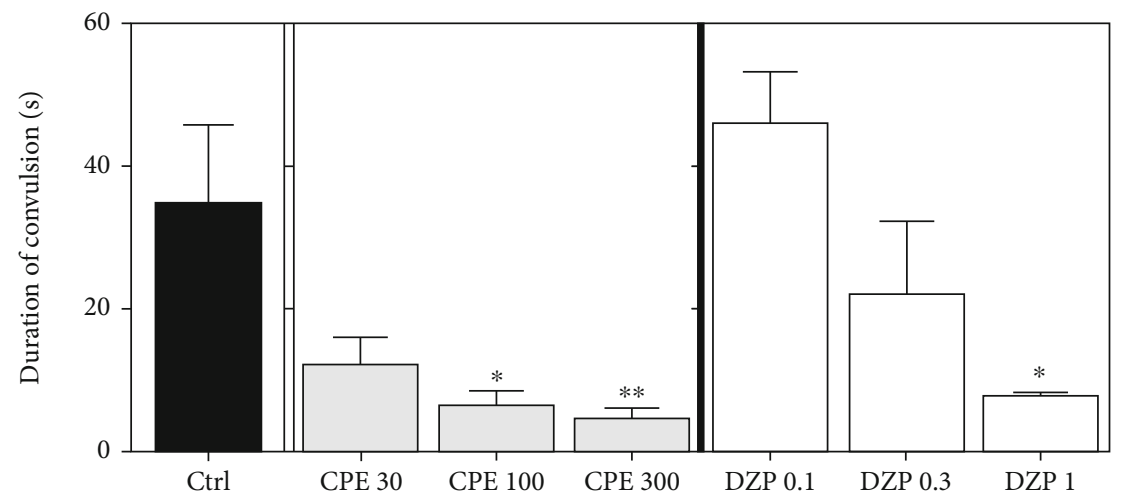

FIGURE 2: Effect of CPE (30-300 mg/kg, p.o.) and diazepam (0.1-1.0 mg/kg, i.p.) on the duration of strychnine-induced clonic seizures in mice. Data are expressed as mean \pm S.E.M. $(n=7) .{ }^{* *} p<0.01$ and ${ }^{*} p<0.05$ (one-way ANOVA followed by Tukey's post hoc test).

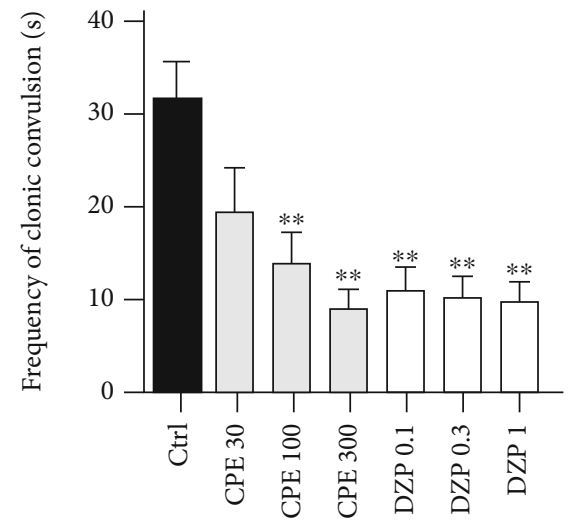

(a)

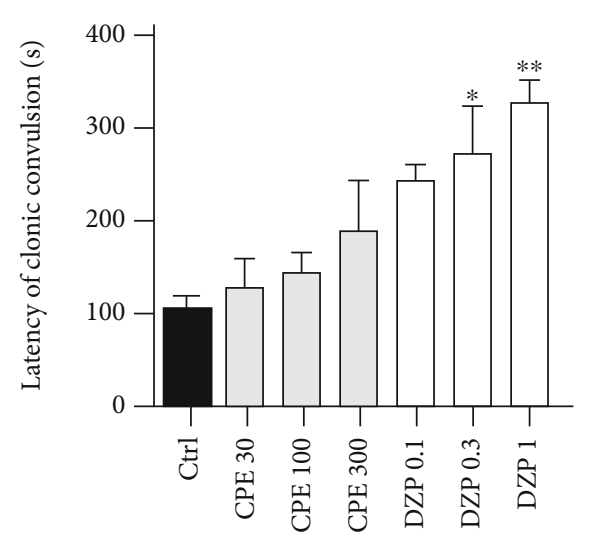

(b)

FIGURE 3: Effect of CPE (30-300 mg/kg, p.o.) and diazepam (0.1-1.0 mg/kg, i.p.) on frequency (a) and latency (b) of strychnine-induced clonic seizures in mice. Data are expressed as mean \pm S.E.M. $(n=7) .{ }^{* *} p<0.01$ and ${ }^{*} p<0.05$ (one-way ANOVA followed by Dunnett's post hoc test).

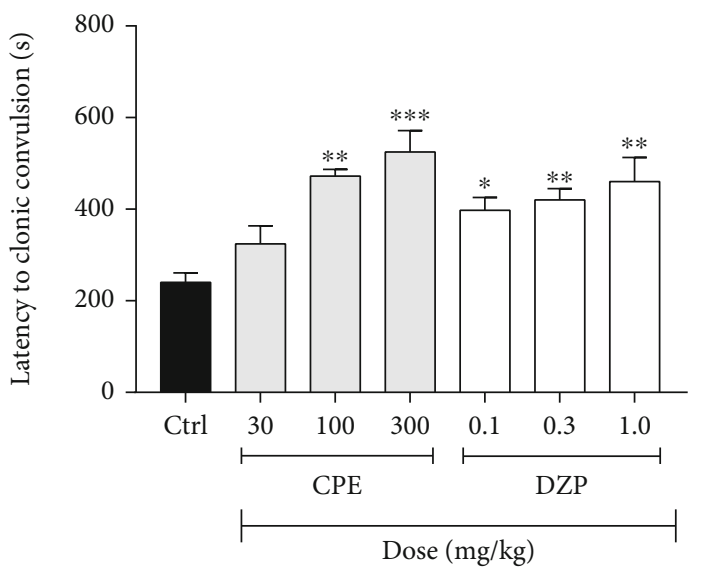

(a)

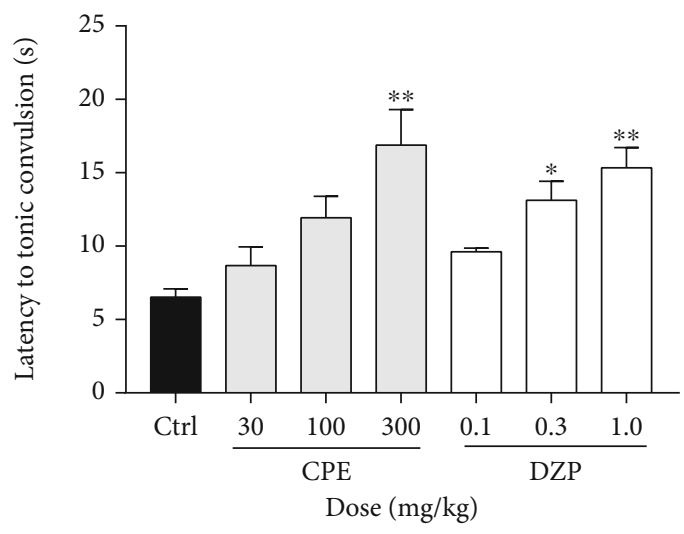

(b)

FIGURE 4: Effect of CPE (30-100 mg/kg, p.o.) and diazepam (0.1-1 mg/kg, i.p.) on the latency to (a) clonic and (b) tonic convulsions in the pilocarpine-induced status epilepticus in mice. Data is presented as mean \pm S.E.M. $(n=7) ;{ }^{* * *} p<0.001 ;{ }^{* *} p<0.01$, and ${ }^{*} p<0.05$ compared to the vehicle-treated group (one-way ANOVA followed by Dunnett's post hoc test). 
way analysis of variance (ANOVA) was used in analysing time-course curves whiles a one-way analysis of variance was employed in determining differences between treatment groups (areas under the curve). GraphPad Prism version 7.0 (GraphPad Software, San Diego, CA) for Windows was used to perform all statistical analyses with $p<0.05$ considered statistically significant for all tests.

\section{Results}

3.1. HPLC Fingerprint. The HPLC chromatogram (Figure 1) revealed 10 peaks representing the various constituents in the $70 \%$ hydroethanolic extract of C. procera leaves. The retention times of the peaks with their respective area and height are represented in Table 1.

3.2. Strychnine-Induced Seizures. Figure 2 indicates the effects of CPE (30-300 mg/kg, p.o.) and diazepam (0.1-1 mg/kg, i.p.) on the duration of clonic convulsions induced by strychnine in mice. The administration of the extract was able to reduce the duration of convulsions as well as reduce the frequency of clonic seizures. However, the extract showed a relatively inadequate ability to delay the onset of these seizures induced by strychnine.

One-way ANOVA revealed that the CPE (100-300 $\mathrm{mg} / \mathrm{kg}$ ) exhibited a dose-dependent anticonvulsant effect against strychnine-induced clonic seizures by significantly reducing the duration of convulsions $(p=0.0068)$. Diazepam $(1 \mathrm{mg} / \mathrm{kg})$ also significantly reduced the duration of strychnine-induced clonic seizures. The extract (100-300 $\mathrm{mg} / \mathrm{kg})$ significantly $(p=0.0016)$ reduced the frequency of clonic convulsions induced by strychnine (Figure 3(a)). However, CPE, at the doses given $(30-300 \mathrm{mg} / \mathrm{kg})$ was unable to increase the latency of strychnine-induced clonic convulsions significantly. Diazepam $(0.3-1 \mathrm{mg} / \mathrm{kg})$ significantly $(p=0.0188)$ delayed the onset of convulsions (Figure 3(b)), and all doses of diazepam administered significantly reduced the frequency of convulsions (Figure 3(a)).

3.2.1. Pilocarpine-Induced Status Epilepticus. One-way ANOVA showed that CPE dose-dependently delayed the onset of clonic $(p=0.0001)$ (Figure $4(\mathrm{a}))$ and tonic convulsions $(p=0.0001)$ (Figure 4(b)). Diazepam, the reference anticonvulsant agent (DZP $0.1-1.0 \mathrm{mg} / \mathrm{kg}$ ), showed similar effects as the extract by increasing the latencies to clonic and tonic convulsions. The oral dose of CPE (100-300 mg/kg) showed a profound anticonvulsant effect by protecting the animals against death, which was caused by the convulsions induced by pilocarpine (Figure 5) (hazard ratio $=0.1819, p$ $<0.0021) . \mathrm{ED}_{50}(\sim 0.1007)$ and $E_{\max }$ values calculated from the dose-response curves (Figure 6) demonstrated that the extract was less potent than diazepam in reducing the duration of convulsions and delaying the onset of convulsions, but their efficacies were comparable.

3.2.2. Isoniazid-Induced Seizure Model. The extract, CPE, significantly prolonged the onset of and survival in seizures induced by isoniazid in mice. Analysis of the results showed that CPE $\left(300 \mathrm{mg} \mathrm{kg}^{1}\right.$, p.o. $)$ delayed the onset of the seizure $(p<0.001)$ as shown in Figure 7(a). Diazepam showed simi-

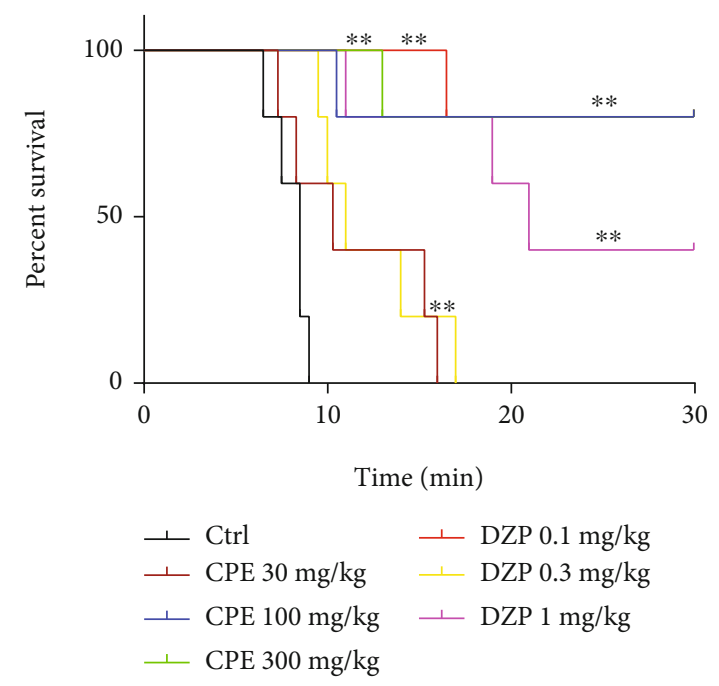

Figure 5: Percentage survival of mice for extract $(30-300 \mathrm{mg} / \mathrm{kg}$ ) and diazepam $(0.1-1 \mathrm{mg} / \mathrm{kg}$, i.p.). Each point is the mean \pm S.E.M. of 7 animals.

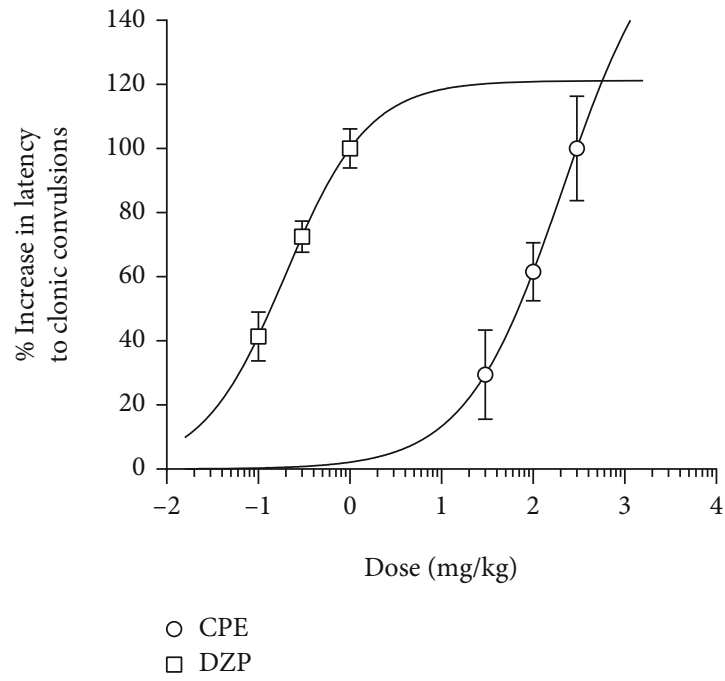

FIGURE 6: Dose-response curve for the anticonvulsant activity induced by the administration of CPE (30-100 mg/kg, p.o.) and diazepam (0.1-1 mg/kg, i.p.) in the pilocarpine-induced seizure test in mice.

lar effects with the highest dose $(1 \mathrm{mg} / \mathrm{kg}$ significant at $p<$ $0.01)$. The extract CPE (100-300 $\mathrm{mg} / \mathrm{kg})$ again exhibited anticonvulsant action by protecting (prolonged latency to death) animals against death, which was caused by the convulsions induced by isoniazid (Figure 7(b)).

3.2.3. Picrotoxin-Induced Seizures. The extract-treated groups exhibited a significant anticonvulsant effect in this model. CPE $(100-300 \mathrm{mg} / \mathrm{kg})$ caused a profound dosedependent delay in the onset of clonic convulsions $(p<0.0001)$ (Figure $8(\mathrm{a}))$ and tonic convulsions in mice $(p<0.0001)$ (Figure 8(b)). The extract also decreased the duration of convulsions significantly in clonic $(p<0.0001)$ (Figure 9(a)) and tonic $(p<0.0001)$ convulsions 

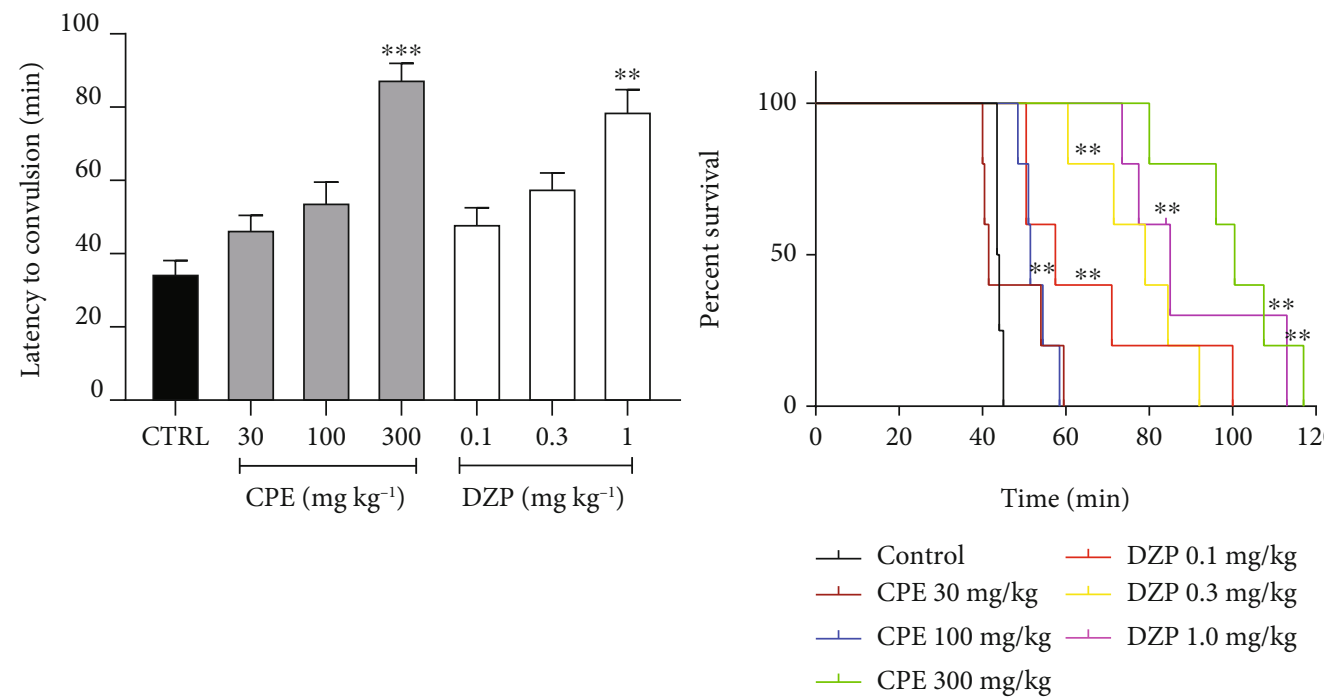

Figure 7: Effect of extract (CPE 30-300 mg/kg, p.o.) and diazepam (DZP 0.1-1.0 $\mathrm{mgkg}^{-1}$, i.p.) on the latency to convulsion and survival time curve of isoniazid-induced epilepsy in mice. Data is presented as mean \pm S.E.M. $(n=7) ;{ }^{* * *} p<0.001 ;{ }^{* *} p<0.01$ compared to the vehicletreated group (one-way ANOVA followed by Dunnett's post hoc test).

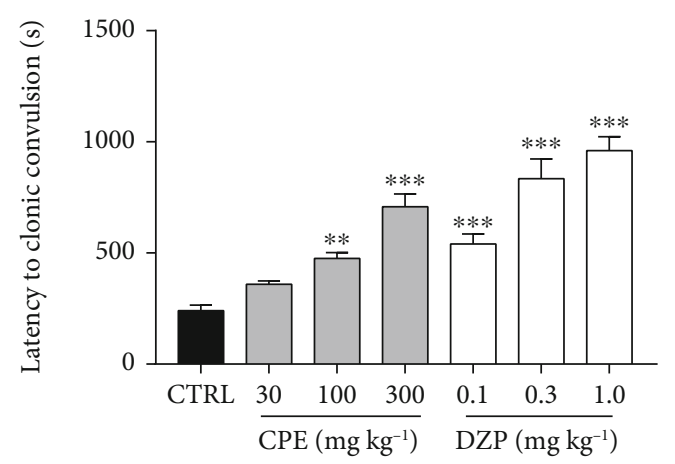

(a)

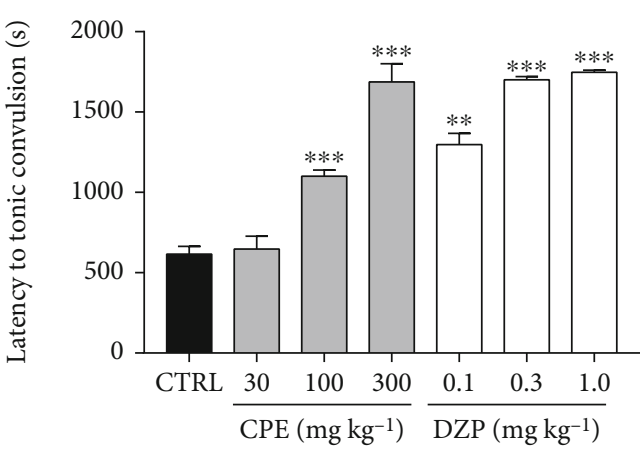

(b)

Figure 8: Effect of CPE (30-300 mg/kg, p.o.) on the latency to (a) clonic convulsion and (b) tonic convulsions in the picrotoxin-induced seizure test in mice. Data are presented as mean \pm S.E.M. $(n=7)$; ${ }^{* * *} p<0.001$; ${ }^{* *} p<0.01$; compared to the control group (one-way ANOVA followed by Dunnett's post hoc test).

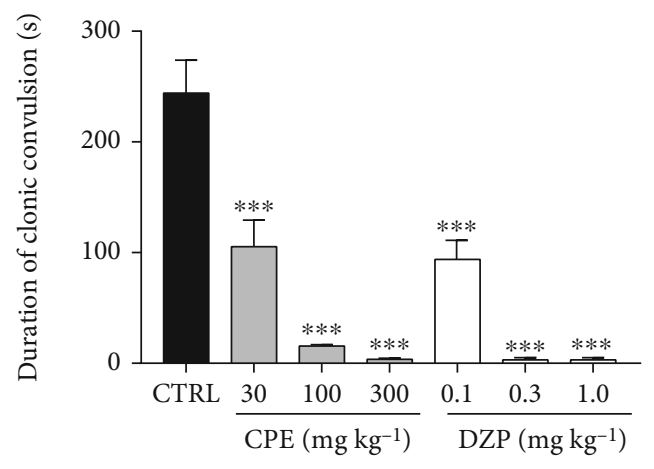

(a)

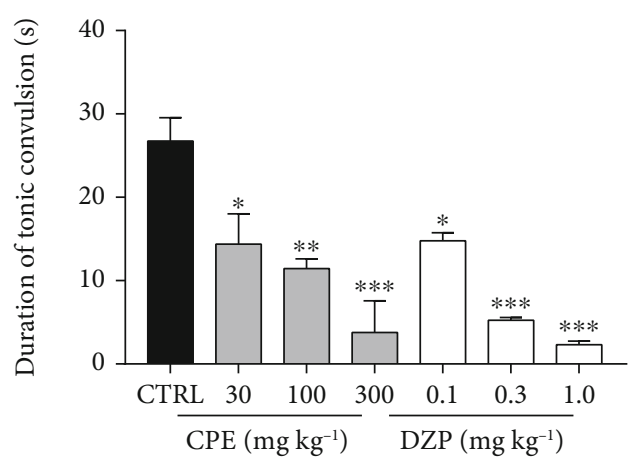

(b)

FiguRE 9: Effect of CPE (30-300 mg/kg, p.o.) on the duration of convulsions in the picrotoxin-induced seizure test in mice. Data are presented as mean \pm S.E.M. $(n=7) ;{ }^{* * *} p<0.001{ }^{* *} p<0.01 ;{ }^{*} p<0.05$ compared to the control group (one-way ANOVA followed by Dunnett's post hoc test). 


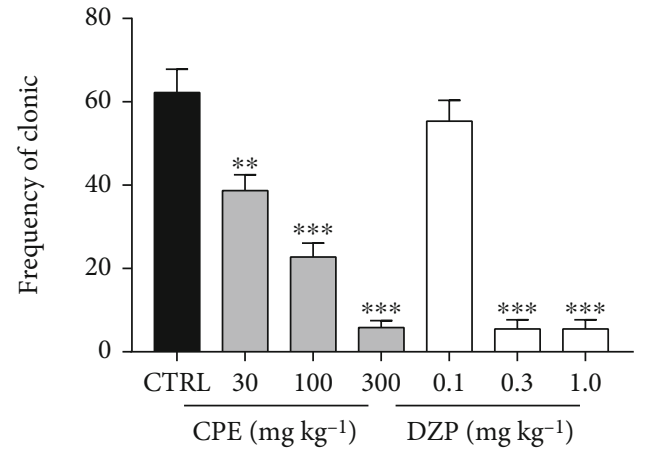

(a)

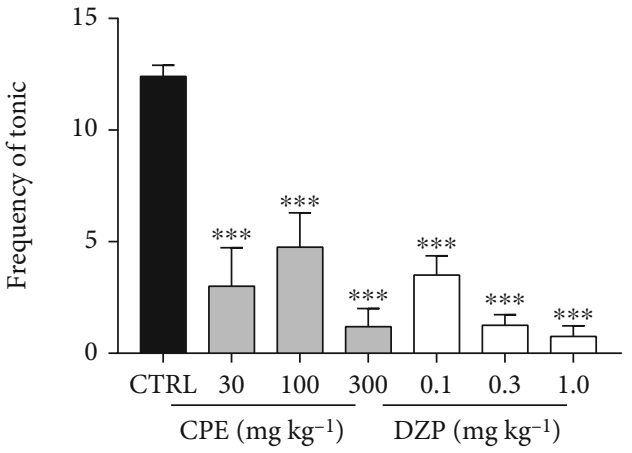

(b)

Figure 10: Effect of CPE $(30-300 \mathrm{mg} / \mathrm{kg}$, p.o.) on the frequency of convulsions in the picrotoxin-induced seizure test in mice. Data are presented as mean \pm S.E.M. $(n=7) ;{ }^{* * *} p<0.001$ and ${ }^{* *} p<0.01$ compared to the control group (one-way ANOVA followed by Dunnett's post hoc test).

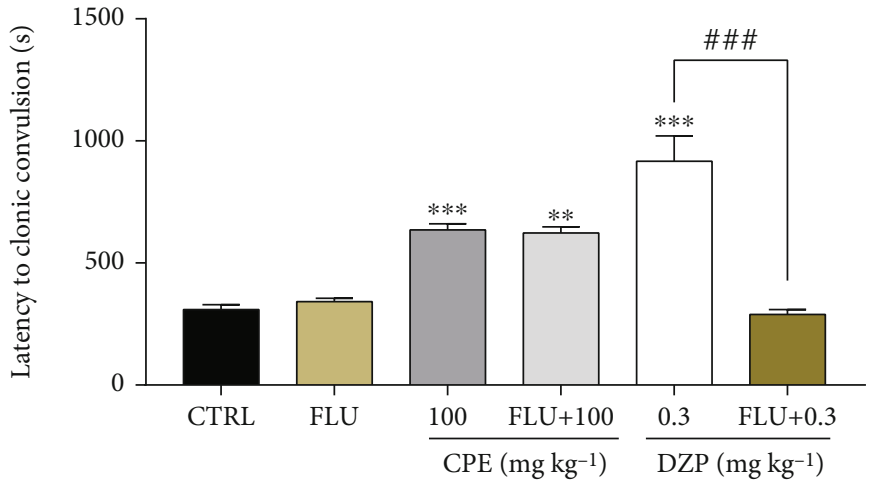

(a)

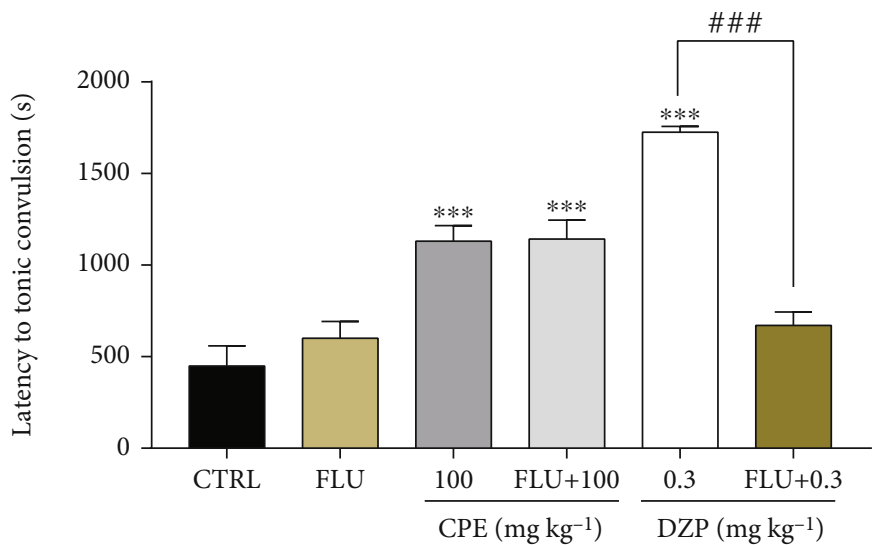

(b)

Figure 11: Effect of flumazenil on the anticonvulsant effect (latency to convulsion) of CPE (100 mg/kg, p.o.). (a) Latency to clonic and (b) latency to tonic convulsion in the picrotoxin-induced seizure test in mice. Data are presented as mean \pm S.E.M. $(n=7)$; ${ }^{* * * *} p<0.0001$; ${ }^{* * *} p<0.001$, and ${ }^{* *} p<0.01$; compared to the vehicle-treated group (One-way ANOVA followed by Dunnett's post hoc test). ${ }^{\# \# \#} p<0.001$ compared to the diazepam-treated group.

(Figure 9(b)). Diazepam $(0.1-1.0 \mathrm{mg} / \mathrm{kg}$ ), the reference anticonvulsant, showed similar results as the extract by increasing the latencies to clonic and tonic convulsions and the duration of convulsions. The frequencies of convulsions were also reduced significantly in both clonic $(p<0.0001)$ and tonic $(p<0.0001)$ seizures (Figure 10).

3.2.4. Involvement of GABAergic Mechanism. From the results obtained, CPE alone delayed the onset, duration, and frequency of convulsions just like diazepam alone (Figures 11-13). Flumazenil alone $(2 \mathrm{mg} / \mathrm{kg}$, i.p.) did not alter the onset or duration of convulsions. Pretreatment with flumazenil could not inhibit the anticonvulsant effect of the extract but significantly reversed the onset of clonic $(p<0.0001)$ and tonic $(p<0.0001)$ convulsions; the duration of clonic $(p<0.0001)$ and tonic $(p<0.0001)$; and frequency of clonic $(p<0.0001)$ and tonic $(p<0.0001)$ convulsion effect of diazepam in the picrotoxin-induced seizure model.

\section{Discussion}

To ensure correct identification and authentication of the C. procera leaf extract, an HPLC fingerprint was developed. HPLC fingerprint analysis of plant extracts provides information on the retention time of the constituents in a plant extract as a quality control method for identifying and assessing the stability of the plant extract [20]. The chromatogram revealed the presence of five (5) peaks showing the retention time of 2.5-3.1 minutes suggesting the presence of highly polar constituents. Five (5) peaks showed between 15 and 17.3 minutes suggesting the presence of relatively nonpolar constituents in the hydroethanolic extract of $C$. procera. This was similar to other earlier reports [16]. The peaks at retention times of 3.050 and 17.263 could be attributed to the presence of catechol and calotoxin, respectively, as reported [15]. The HPLC fingerprint provided in this work would be beneficial for identifying and assessing the quality of the $70 \%$ hydroethanolic extract of the leaves of $C$. procera. Again the results from the HPLC forms the basis for the isolation and 


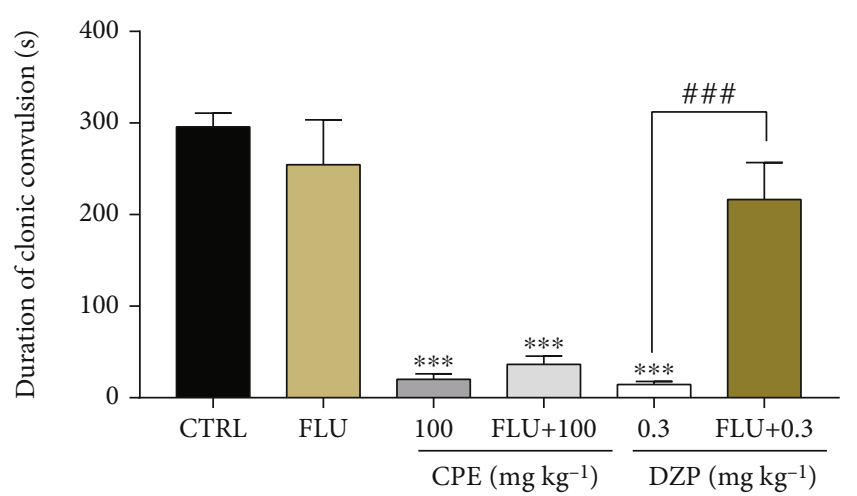

(a)

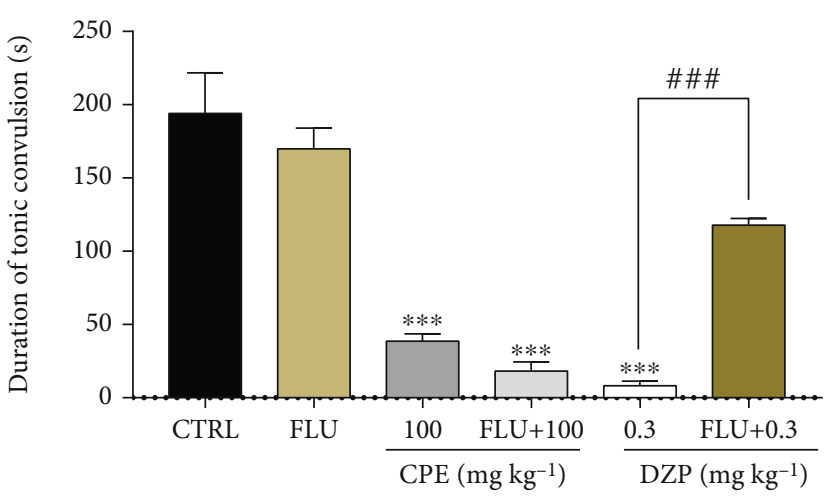

(b)

Figure 12: Evaluation of GABAergic involvement on the duration of (a) clonic and (b) tonic seizures in the picrotoxin-induced seizure test in mice treated with CPE $(100 \mathrm{mg} / \mathrm{kg}, p . o$.$) . Data are presented as mean \pm$ S.E.M. $(n=7) ;{ }^{* * * *} p<0.0001 ;{ }^{* * *} p<0.001$, compared to the vehicletreated group (one-way ANOVA followed by Dunnett's post hoc test). ${ }^{\# \#} p<0.001$ compared to the diazepam-treated group.

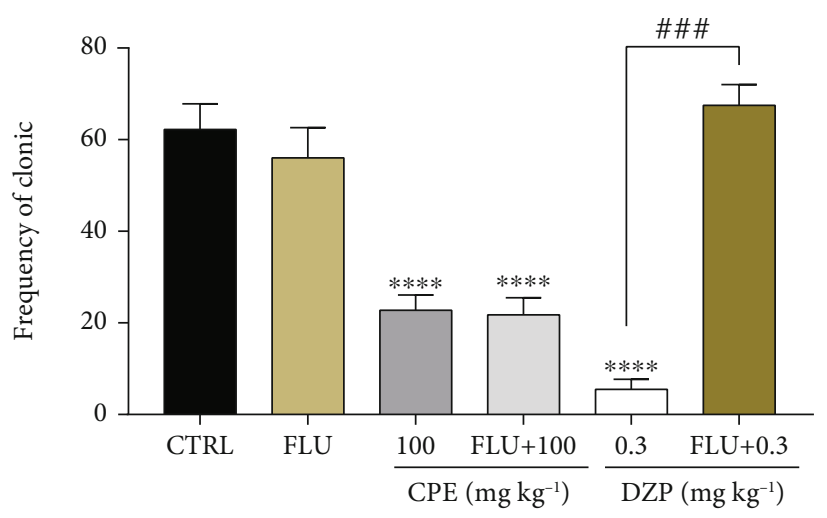

(a)

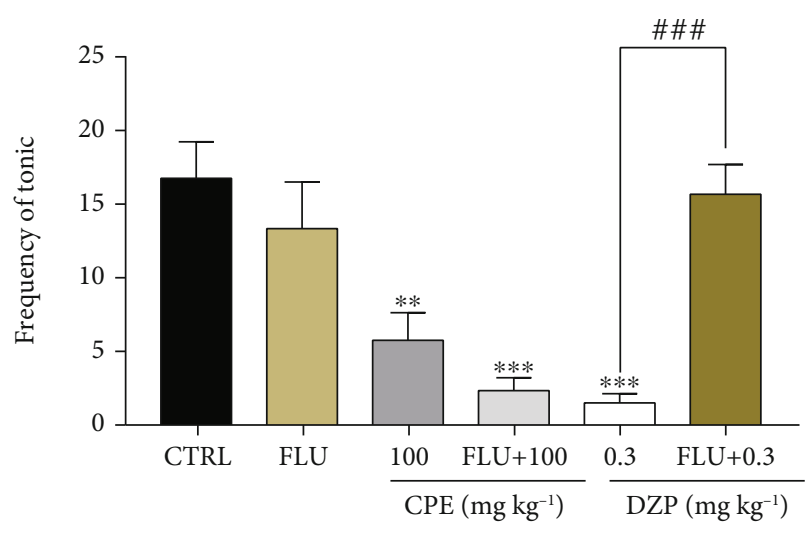

(b)

FIgURE 13: Evaluation of GABAergic involvement on the frequency of (a) clonic and (b) tonic seizures in the picrotoxin-induced seizure test in mice treated with CPE $(100 \mathrm{mg} / \mathrm{kg}, p . o$.$) . Data are presented as mean \pm$ S.E.M. $(n=7) ;{ }^{* * * *} p<0.0001 ;{ }^{* * *} p<0.001$; compared to the vehicle-treated group (one-way ANOVA followed by Dunnett's post hoc test). ${ }^{\# \# \#} p<0.001$ compared to the diazepam-treated group.

characterization of compounds from the extract in future studies.

It is clear from the studies conducted that oral administration of Calotropis procera leaf extract mitigates convulsions in both generalized and acute seizure models-pentylenetetrazole, picrotoxin, and strychnineinduced seizure tests, respectively, and partial seizure models; the pilocarpine-induced Status epilepticus and the isoniazidinduced seizures.

The glycine receptor is liable for the regulation of strong inhibitory neurotransmission in the mature central nervous system [21], which makes this receptor a prospective target for antiepileptic drugs $[22,23]$. Strychnine induces seizures by blocking the activity of strychnine-sensitive glycine receptors and increased postsynaptic excitability and sustained action in the brainstem and spinal cord [23, 24]. Since the extract decreased the frequency and duration of convulsions caused by strychnine, a possibility of the extract interacting with glycine receptors/pathways is conceivable. The extract may contain bioactive compounds that activate glycinergic inhibitory neurotransmission.
An animal model of intractable epilepsy is the systemic administration of pilocarpine, a nonselective muscarinic agonist $[8,18,25-27]$. Histological studies have shown that this model has important similarities to temporal lobe epilepsy in humans, and thus, in this model, successful drugs are possible candidates for the treatment of temporal lobe epilepsy $[8,28-31]$. The extract was able to protect the animals from death from acute convulsions described as status epilepticus induced by pilocarpine. Consequently, in the treatment of temporal lobe epilepsy and/or other partial seizures, the extract may be of possible use. This is evidenced in the survival curve drawn and the hazard ratio calculated. The lower the hazard ratio, the better the treatment as there is a low risk of death compared to an untreated population [32].

Alkaloids, saponins, and sterols, which are identified secondary metabolites in the plant, may be responsible for the anticonvulsant effect of the extract. [12].

Status epilepticus by isoniazid is related to the inhibition of glutamate decarboxylase (GAD), an enzyme required for GABA synthesis [33-36]. Again, decreased levels of GABA in the brain are associated with ongoing seizures seen in 
animals exposed to high amounts of isoniazid [35]. The depletion of pyridoxine caused using INH leads to decreased development of GABA, as it is normally a result of a decarboxylation reaction that is based on pyridoxine. GABA deficiency can therefore present itself as seizures, especially in the acute toxicity environment [8].

Diazepam was only effective at its highest dose on the latency to death. The variability and immediate availability of the amount of INH ingested are also the key drawbacks to the effectiveness of DZP in the treatment of isoniazid toxicity clinically. [8, 37]. Again, previous studies revealed that anticonvulsant agents do not depend on the prevention of convulsion but on their ability to prolong the latency to seizures [38]. Moreover, compounds that only delay the latency to convulsions block the spread of seizures in an epileptic brain.

Picrotoxin is a $\mathrm{GABA}_{\mathrm{A}}$ receptor antagonist [39]. Picrotoxin confers its convulsive activity by blocking the chloride ion channel linked to the $\mathrm{GABA}_{\mathrm{A}}$ receptor, which normally unlocks to allow increased chloride ion conductance into the brain cells after $\mathrm{GABA}_{\mathrm{A}}$ receptor activation by gammaaminobutyric acid [40-42]. GABAergic ionotropic receptors can mediate both pre-and postsynaptic inhibition. Presynaptic inhibition mediated by GABA often leads to inhibition of neurotransmitter release from the excitatory arm [43]. The extract, being effective in the picrotoxin-induced seizure test, points to action on GABA-mediated neurotransmission.

Many barbiturates and benzodiazepines generally potentiate the inhibitory action of $\mathrm{GABA}_{\mathrm{A}}$ receptors, reducing neuronal excitability and increasing the threshold for convulsions [44]. Since CPE displayed effectiveness in both pentylenetetrazole-induced seizures and picrotoxin-induced seizures, a possible association with GABAergic mechanisms was investigated using flumazenil, a benzodiazepine receptor antagonist [45], using the picrotoxin-induced seizure test. However, in this test, flumazenil was unable to reverse the antiseizure effect characterised by CPE and this indicates a potentially different or complex mechanism involved in the attenuation of convulsion by the Calotropis procera extract.

These results are consistent with studies conducted previously on the aqueous extract of leaves of Calotropis procera in pentylenetetrazole-induced seizures [46]. The aqueous extract increased the onset and duration of convulsions but showed no change in the levels of GABA. This provides further evidence that the mechanism by which the plant exerts its anticonvulsant action may be through a different pathway.

The models employed in this study provide a very good basis for further studies on C. procera as an antiepileptic agent. Because compounds were not isolated in this study from the crude extract, the mechanism (s) by which the extract produces its effects cannot be attributed to a specific compound in the plant. Subsequent studies may seek to isolate bioactive substances from the crude extract and determine the precise receptor interactions of these isolates in their anticonvulsant activity.

\section{Conclusion}

These findings demonstrated an anticonvulsant effect of the extract. CPE activation of the GABAergic system may be absent but may act through glycinergic systems. The anticonvulsant effect exhibited makes the extract a likely therapeutic potential for both generalised and partial seizure events.

\section{Data Availability}

The data in support of the findings in this study may be requested and obtained from the corresponding author.

\section{Conflicts of Interest}

The authors declare there is no conflict of interest.

\section{Authors' Contributions}

Ernest Obese and Robert Peter Biney are co-first authors.

\section{Acknowledgments}

We appreciate all laboratory technologists of the School of Pharmacy and Pharmaceutical Sciences, UCC.

\section{References}

[1] WHO, Epilepsy, 2019, Retrieved from https://www.who.int/ news-room/fact-sheets/detail/epilepsy.

[2] E. Beghi, G. Giussani, E. Nichols et al., "Global, regional, and national burden of epilepsy, 1990-2016: a systematic analysis for the Global Burden of Disease Study 2016," The Lancet Neurology, vol. 18, no. 4, pp. 357-375, 2019.

[3] G. D. Naimo, M. Guarnaccia, T. Sprovieri et al., "A systems biology approach for personalized medicine in refractory epilepsy," International Journal of Molecular Sciences, vol. 20, no. 15, p. 3717, 2019.

[4] B. L. Clossen and D. S. Reddy, "Novel therapeutic approaches for disease-modification of epileptogenesis for curing epilepsy," Biochimica et Biophysica Acta (BBA)-Molecular Basis of Disease, vol. 1863, no. 6, pp. 1519-1538, 2017.

[5] P. R. Choudhury, A. D. Talukdar, D. Nath, P. Saha, and R. Nath, "Traditional Folk Medicine and Drug Discovery: prospects and outcome," Advances in Pharmaceutical Biotechnology: Recent Progress and Future Applications, vol. 3, 2020.

[6] P. K. Mante, D. W. Adongo, E. Woode, K. K. E. Kukuia, and E. O. Ameyaw, "Anticonvulsant effect of Antiaris toxicaria (Pers.) Lesch. (Moraceae) aqueous extract in rodents," International Scholarly Research Notices: Pharmacology, vol. 2013, 2013.

[7] D. W. Adongo, P. K. Mante, E. Woode, E. O. Ameyaw, and K. K. E. Kukuia, "Effects of hydroethanolic leaf extract of Pseudospondias microcarpa (A. Rich.) Engl. (Anacardiaceae) on the central nervous system in mice: the role of excitatory/inhibitory neurotransmission and nitric oxide pathway," Journal of Ethnopharmacology, vol. 206, pp. 78-91, 2014.

[8] K. K. E. Kukuia, E. O. Ameyaw, E. Woode, P. K. Mante, and D. W. Adongo, "Enhancement of inhibitory neurotransmission and inhibition of excitatory mechanisms underlie the anticonvulsant effects of Mallotus oppositifolius," Journal of Pharmacy \& Bioallied Sciences, vol. 8, no. 3, pp. 253-261, 2016.

[9] D. S. Nsagha, C. W. Ayima, T. Nana-Njamen, and J. C. N. Assob, "The role of traditional, complementary/alternative medicine in primary healthcare, adjunct to universal health 
coverage in Cameroon: a review of the literature," American Journal of Epidemiology, vol. 8, no. 1, pp. 37-47, 2020.

[10] Z. Amtul, "Nature's medicines to treat epileptic seizures," in Studies in Natural Products Chemistry, vol. 56, pp. 129-150, Elsevier, 2018.

[11] P. T. Kinda, P. Zerbo, S. Guenné, M. Compaoré, A. Ciobica, and M. Kiendrebeogo, "Medicinal plants used for neuropsychiatric disorders treatment in the Hauts Bassins region of Burkina Faso," Medicine, vol. 4, no. 2, p. 32, 2017.

[12] E. Obese, E. O. Ameyaw, R. P. Biney, I. T. Henneh, F. J. Edzeamey, and E. Woode, "Phytochemical screening and antiinflammatory properties of the hydroethanolic leaf extract of Calotropis procera (Ait). R. Br. (Apocynaceae)," Journal of Pharmaceutical Research International, vol. 23, no. 1, pp. 111, 2018.

[13] A. Vezzani, R. S. Fujinami, H. S. White et al., "Infections, inflammation and epilepsy," Acta Neuropathologica, vol. 131, no. 2, pp. 211-234, 2016.

[14] A. Hawrył, M. Hawrył, and M. Waksmundzka-Hajnos, "Liquid chromatography fingerprint analysis and antioxidant activity of selected lavender species with chemometric calculations," PloS one, vol. 14, no. 7, 2019.

[15] K. H. Richa and S. Shikha, "Phytochemical investigations and anatomical study of two species of Calotropis from Chandigarh," International Journal of Pharmaceutical Sciences and Research, vol. 6, no. 4, 2015.

[16] E. Obese, R. P. Biney, I. T. Henneh et al., "Antinociceptive effect of the hydroethanolic leaf extract of Calotropis procera (Ait) R. Br. (Apocynaceae): Possible involvement of glutamatergic, cytokines, opioidergic and adenosinergic pathways," Journal of Ethnopharmacology, vol. 278, p. 114261, 2021.

[17] N. N. Bogdanov, I. I. Poletaeva, and N. V. Popova, "Pentylenetetrazol and strychnine convulsions in brain weight selected mice," Seizure, vol. 6, no. 2, pp. 135-138, 1997.

[18] L. Turski, C. Ikonomidou, W. A. Turski, Z. A. Bortolotto, and E. A. Cavalheiro, "Review: cholinergic mechanisms and epileptogenesis. The seizures induced by pilocarpine: a novel experimental model of intractable epilepsy," Synapse, vol. 3, no. 2, pp. 154-171, 1989.

[19] S. Asehinde, A. Ajayi, A. Bakre, O. Omorogbe, A. Adebesin, and S. Umukoro, "Effects of Jobelyn ${ }^{\circledR}$ on isoniazid-induced seizures, biomarkers of oxidative stress and glutamate decarboxylase activity in mice," Basic and clinical neuroscience, vol. 9, no. 6, pp. 389-396, 2018.

[20] G. Shams, H. F. Ismail, T. L. Chee et al., "Development of HPLC fingerprint analysis of traditional diabetes herbal Jamu diabetes plant materials," Jurnal Teknologi, vol. 68, no. 1, 2014.

[21] T. I. Webb and J. W. Lynch, "Molecular pharmacology of the glycine receptor chloride channel," Current Pharmaceutical Design, vol. 13, no. 23, pp. 2350-2367, 2007.

[22] M. J. Sheardown, J. Drejer, L. H. Jensen, C. E. Stidsen, and T. Honoré, "A potent antagonist of the strychnine insensitive glycine receptor has anticonvulsant properties," European Journal of Pharmacology, vol. 174, no. 2-3, pp. 197-204, 1989.

[23] B. Sadek, M. Oz, S. M. Nurulain et al., "Phenylalanine derivatives with modulating effects on human $\alpha 1$-glycine receptors and anticonvulsant activity in strychnine-induced seizure model in male adult rats," Epilepsy Research, vol. 138, pp. 124-131, 2017.

[24] L. F. Wang, M. L. Zhao, and Y. Liu, "Experimental pharmacodynamic study on the anti-convulsion effect of shenpu decoc- tion," Zhongguo Zhong Xi Yi Jie He Za Zhi, vol. 21, no. 11, pp. 837-839, 2001.

[25] R. M. Eglen, A. Choppin, and N. Watson, “Therapeutic opportunities from muscarinic receptor research," Trends in Pharmacological Sciences., vol. 22, no. 8, pp. 409-414, 2001.

[26] N. R. Mirza, D. Peters, and R. G. Sparks, "Xanomeline and the antipsychotic potential of muscarinic receptor subtype-selective agonists," CNS Drug Reviews, vol. 9, no. 2, pp. 159-186, 2003.

[27] D. Wirtshafter, "The selective m1 muscarinic antagonist MT-7 blocks pilocarpine-induced striatal Fos expression," Brain Research, vol. 1085, no. 1, pp. 127-131, 2006.

[28] Z. Liu, T. Nagao, G. C. Desjardins, P. Gloor, and M. Avoli, "Quantitative evaluation of neuronal loss in the dorsal hippocampus in rats with long-term pilocarpine seizures," Epilepsy Research, vol. 17, no. 3, pp. 237-247, 1994.

[29] C. J. Wall, E. J. Kendall, and A. Obenaus, "Rapid alterations in diffusion-weighted images with anatomic correlates in a rodent model of status epilepticus," American Journal of Neuroradiology, vol. 21, no. 10, pp. 1841-1852, 2000.

[30] J. Szyndler, T. Wierzba-Bobrowicz, A. Skorzewska et al., "Behavioral, biochemical and histological studies in a model of pilocarpine- induced spontaneous recurrent seizures," Pharmacology Biochemistry and Behavior, vol. 81, no. 1, pp. 15-23, 2005.

[31] P. Perez-Mendes, M. M. Blanco, M. E. Calcagnotto et al., "Modeling epileptogenesis and temporal lobe epilepsy in a non-human primate," Epilepsy Research, vol. 96, no. 1-2, pp. 45-57, 2011.

[32] H.-C. Chen, R. L. Kodell, K. F. Cheng, and J. J. Chen, “Assessment of performance of survival prediction models for cancer prognosis," BMC Medical Research Methodology, vol. 12, no. 1, 2012.

[33] S. Bassin, T. L. Smith, and T. P. Bleck, "Clinical review: status epilepticus," Critical Care, vol. 6, no. 2, pp. 137-142, 2002.

[34] A. C. Bronstein, D. A. Spyker, L. R. Cantilena, J. L. Green, B. H. Rumack, and R. C. Dart, "Annual report of the American Association of Poison Control Centers' National Poison Data System (NPDS): 28th annual report," Clinical Toxicology, vol. 49, pp. 910-941, 2010.

[35] M. G. Corda, E. Costa, and A. Guidotti, "Specific proconvulsant action of an imidazobenzodiazepine (Ro 15-1788) on isoniazid convulsions," Neuropharmacology, vol. 21, no. 1, pp. 91-94, 1982.

[36] M. U. Cevik, A. Acar, H. Tanriverdi et al., "Toxic effects of isoniazid and rifampicin on rat brain tissue: the preventive role of caffeic acid phenethyl ester," International Journal of Pharmacology, vol. 8, no. 6, pp. 555-560, 2012.

[37] A. B. Minns, N. Ghafouri, and R. F. Clark, "Isoniazid-induced status epilepticus in a pediatric patient after inadequate pyridoxine therapy," Pediatric Emergency Care, vol. 26, no. 5, pp. 380-381, 2010.

[38] D. A. Kendall, D. A. Fox, and S. J. Enna, "Effect of $\gamma$-vinyl GABA on bicuculline-induced seizures," Neuropharmacology, vol. 20, no. 4, pp. 351-355, 1981.

[39] R. W. Olsen, "GABA-benzodiazepine-barbiturate receptor interactions," Journal of Neurochemistry, vol. 37, no. 1, pp. 1-13, 1981.

[40] R. A. Nicoll, "Introduction to the pharmacology of CNS drugs," in Basic and Clinical Pharmacology, B. G. Katzung, Ed., Lange Medical Books/McGraw-Hill, New York, 8th edition, 2001. 
[41] L. Velíšek, Models of Seizures and Epilepsy, Academic Press, 2006.

[42] V. Kumar, "Potential medicinal plants for CNS disorders: an overview," Phytotherapy Research, vol. 20, no. 12, pp. 10231035, 2006.

[43] A. B. Macdermott, L. W. Role, and S. A. Siegelbaum, "Presynaptic ionotropic receptors and the control of transmitter release," Annual Review of Neuroscience, vol. 22, no. 1, pp. 443-485, 1999.

[44] W. Löscher, "Animal models of epilepsy for the development of anti-epileptogenic and disease-modifying drugs. A comparison of the pharmacology of kindling and post-status epilepticus models of temporal lobe epilepsy," Epilepsy Research, vol. 50, no. 1-2, pp. 105-123, 2002.

[45] E. Przegalinski, E. Tatarczynska, and E. Chojnacka-Wojcik, "The influence of the benzodiazepine receptor antagonist flumazenil on the anxiolytic-like effects of CGP 37849 and ACPC in rats," Neuropharmacology, vol. 39, no. 10, pp. 1858-1864, 2000.

[46] V. Ramachandra, S. Shenoy, M. Madhyastha, R. Desai, and S. Ghosh, "Evaluation of effect of aqueous extract of leaves of Calotropis procera in pentylenetetrazole induced seizures in rats," International Journal of Basic \& Clinical Pharmacology, vol. 5, no. 3, pp. 643-646, 2016. 